\title{
Una mirada a la Facultad de Odontología en su 75 Aniversario
}

La celebración de cada aniversario de la Facultad nos invita a partir de una perspectiva reflexiva, a mirar hacia atrás para recordar desde nuestros orígenes de el presente, con el fin de valorar lo que estamos haciendo y lo que hemos logrado, y al futuro, para ver hacia dónde vamos y los desafíos que debemos superar.

La Facultad de Odontología, a sus 75 años de historia académica, centrada en los tres ejes sustantivos de la Universidad de Costa Rica (Docencia, Investigación y Acción Social), permite visualizar la presencia de la integralidad en la formación del nuevo profesional y los retos que la salud bucodental de la población del país presenta, para responder como unidad académica reacreditada, con el compromiso de entregar al país "un graduado con formación integral humanista con excelencia académica y, una sólida formación técnica y científica en su campo profesional...y enmarcado en el contexto de la promoción de la salud y la prevención de la enfermedad" planteado en el perfil profesional de la carrera de la Licenciatura en Odontología, aprobado en Asamblea de Facultad 05-07 (1).

En este contexto, el cambio ha sido, una constante que permite adaptarnos a las necesidades de la sociedad costarricense y a la evolución natural de la odontología, tal es el caso del plan de estudios de la carrera que, ha pasado por diferentes procesos de revisión y reestructuración, respondiendo al estado del arte. Así como la propia facultad, que en los últimos 25 años ha experimentado dos reorganizaciones administrativas y docentes de acuerdo con el criterio de expertos de la época y en pro de mejorar su calidad en el año 1986 llevó a cabo un análisis general del modelo docente que se tenía y se modificó su organigrama. En 1996, se planteó una reforma curricular y administrativa por departamentos académicos y la creación de la Dirección de Servicios Odontológicos y Laboratorios (Disol), vigente hoy en día. Posteriormente, en el año 2005 se efectuó la última reforma curricular, aprobada en la Resolución VD-R-7743-2005. A pesar de estos cambios, el plan de estudios mantiene la misma concepción curricular de 1989 (2).

Durante los últimos años, la Universidad de Costa Rica ha procurado institucionalizar los procesos de autoevaluación y autorregulación, acorde con los principios, propósitos y funciones establecidos en el Estatuto Orgánico (3). La Facultad de Odontología no ha sido la excepción, cumpliendo con los procesos de autoevaluación con fines de Acreditación, iniciados el 25 de marzo del año 2003, cuando la Asamblea de Facultad, bajo la Decanatura del Dr. Carlos Filloy Esna, quien tuvo una visión y claro compromiso con el mejoramiento de la calidad de la carrera decidió unánimemente someterse a estos procesos (4-5), lograda en la sesión del Consejo del SINAES No. 553 (artículo No. 8), celebrada el 30 de abril del 2009. Esta entidad acreditó la carrera de la Licenciatura en Odontología de la Universidad de Costa Rica, Sede Rodrigo Facio, por un periodo de 4 años y firmada el 15 de junio del 2009 por parte de la Facultad de Odontología y el SINAES (2). 
La acreditación fue un proceso que marcó un hito histórico para la Facultad, ya que, en el marco del compromiso de mejoramiento, la Unidad Académica ha venido planteando y desarrollando acciones concretas que le han conducido al mejoramiento continuo con un abordaje no solo del eje académico, sino también del talento humano representado en sus docentes y personal administrativo, así como la adquisición de bienes e implementación de nuevos servicios que maximizan los procesos de enseñanzaaprendizaje, y de mejoras de infraestructura.

Sobre este último punto, a nivel institucional se han realizado importantes esfuerzos por dotar a la carrera de un edificio adecuado que potencie su crecimiento y estimule su innovación. En el Componente $\mathrm{N}^{\circ}$ 5: Infraestructura y equipamiento del Compromiso de Mejoramiento del 2009, las diferentes poblaciones, en su momento, refirieron algunas debilidades que afectaban el normal desarrollo de las actividades académicas y la calidad de la enseñanza (6). Entre los puntos más importantes destacó el tamaño insuficiente y la condición del edificio actual, que no permite evolucionar ni expandirse para cumplir con los requisitos de la carrera, igual que se mencionó en el proceso de reacreditación del año 2016.

Esta es una realidad ineludible, considerando que la actual infraestructura cuenta con más de 50 años de antigüedad y a lo largo de las décadas ha sufrido muchos cambios en un esfuerzo por adecuarla a las necesidades de la Licenciatura en Odontología. Sin embargo, para efectos de nuestra academia, ya no cumple con las condiciones idóneas para el desarrollo de las diferentes actividades docentes, de acción social e investigación, por lo cual desde el año 2003 con el apoyo de los diferentes rectores Dr. Gabriel Macaya Trejos, Dra. Yamileth González García, y Dr. Henning Jensen Pennington, se planteó y consolidó el proyecto para la construcción de un edificio nuevo.

Actualmente el edificio alberga una población de aproximadamente 600 estudiantes, a lo que se debe sumar el personal docente, administrativo y pacientes, siendo más de 1000 personas las que diariamente transitan por él. Casi todos los cursos de la malla curricular incluyen pre-clínica y clínica, lo que dificulta la programación de clases debido al reducido número de aulas, laboratorios y ambientes clínicos. Nuestra facultad solo dispone de un laboratorio para 90 estudiantes, un auditorio con capacidad para 100 personas y un aula (001) para 85 alumnos. Esto ha ocasionado que algunos cursos teóricos se deban programar en otras unidades y para las clínicas y laboratorios ha sido necesario habilitar turnos vespertinos, lo que implica la contratación de más personal docente y recargos para el sector administrativo que brinda servicios asociados a la clínica (8).

En el año 2016, la Facultad fue reacreditada por 4 años, siendo la única en el área de la odontología en lograr esa condición en nuestro país. El compromiso de mejoramiento planteado por los pares evaluadores, entre otras cosas, se basa nuevamente en la condición del edificio que se debe mejorar, la necesidad de contar con un expediente electrónico y la evaluación de desempeño de los administrativos.

La Administración se ha esforzado en nivelar las demandas expansivas de la población estudiantil, con claras necesidades de mejora en la infraestructura actual y remodelaciones y mantenimiento en las diferentes áreas, que han permitido continuar y reacreditarse. Se han efectuado reparaciones en algunas clínicas con la instalación nueva de tuberías de agua, aire y electricidad, optimizando las condiciones para la atención de pacientes y del proceso de enseñanza y aprendizaje clínico. 
Hoy en día contamos con rampas de acceso al edificio para las poblaciones con diversidad funcional, un ascensor nuevo para el traslado de todos los grupos humanos y equipos de los estudiantes, así como laboratorios para las poblaciones de V y VI año de la carrera.

Todas estas acciones, denotan el compromiso que tenemos con la búsqueda de la excelencia, dichosamente culminan en este año 2017 con la construcción de un nuevo y moderno edificio, que tendrá los espacios adecuados para continuar con calidad la formación del estudiantado. Si bien este proyecto se veía como un imposible 0 un desarrollo a largo plazo, se ha convertido en una realidad que se concreta cuando estamos celebrando los 75 años de fundación de nuestra querida facultad, justo regalo al esfuerzo conjunto de las diferentes autoridades de la Universidad y de la Unidad Académica, en cumplimiento de la visión de la misma: La Facultad de odontología de la Universidad de Costa Rica será la líder en la formación del grado, posgrado y educación continua, con la más alta excelencia académica y el óptimo desarrollo integral, con una perspectiva humanista, innovadora y emprendedora en la docencia, acción social e investigación; tomando como eje de su quehacer: la promoción y la protección de la salud y prevención de las enfermedades buco-dentomaxilofaciales (1).

Aún con las deficiencias enunciadas, la Facultad camina hacia grandes proyectos e innovaciones que la destacan como pionera en la educación odontológica superior y de avanzada, con miras a promocionar la salud, y manteniéndola, aprovechando los avances tecnológicos en equipamiento para el ejercicio de la interdisciplinariedad y la mejora en el diagnóstico que oriente a un tratamiento acertado y efectivo en pro de la construcción de la salud bucodental de las poblaciones. De ahí que los esfuerzos no solo se han canalizado a nivel de infraestructura, sino también con la adquisición de nuevos equipos y tecnologías.

En congruencia con lo antes citado, la administración se ha comprometido a la minimizar la producción de desechos radiográficos y contaminación ambiental con la radiografía digital (6) reducción del tiempo de exposición de los rayos $X$ que según Shearer et al. _ indican el especial valor en la endodoncia, disciplina que actualmente en la Facultad posee el sistema de radiología con placas de sales de carbono, contribuyendo con el medioambiente y la concientización en el estudiante y futuro profesional, acorde con las políticas universitarias que indican el "Fomentar la inclusión de la dimensión ambiental en las actividades de docencia, investigación y acción social en un marco de inter, multi y transdisciplinariedad, impulsando, además, alianzas estratégicas, tanto entre las diferentes instancias universitarias, como entre éstas y los diversos sectores del país, para fomentar iniciativas que contribuyan con la sostenibilidad ambiental de los espacios universitarios y su entorno" (11).

La odontología como disciplina avanza y cambia constantemente, siempre que se quiera evolucionar, la Facultad lo hace también con ayuda de las autoridades universitarias. Hoy se cuenta con un Tomógrafo Cone Bean (Figura No. 1), para el diagnóstico de cambios y patologías, con el más completo sistema de imágenes odontológicas en 3D, panorámicas y cefalometrías digitales al servicio de la academia, permitiendo al binomio estudiante-profesor valorar en forma integral al paciente y mejorar su tratamiento, con el conocimiento de las limitaciones y usos de la tecnología. Este equipo digital particulariza a la Facultad como una de las pocas universidades a nivel latinoamericano y única en el ámbito nacional que lo poseen. 
Desde el año 2016, la Facultad ha venido adquiriendo equipos de alta tecnología, para complementar la innovación y la formación clínica de alta calidad, que nos permitirá introducir todo un nuevo paradigma en la construcción de coronas, puentes e incrustaciones con equipo SIRONA, con el fin de que el estudiante conozca desde su escaneo, diseño, colocación y cementado de las prótesis fijas.
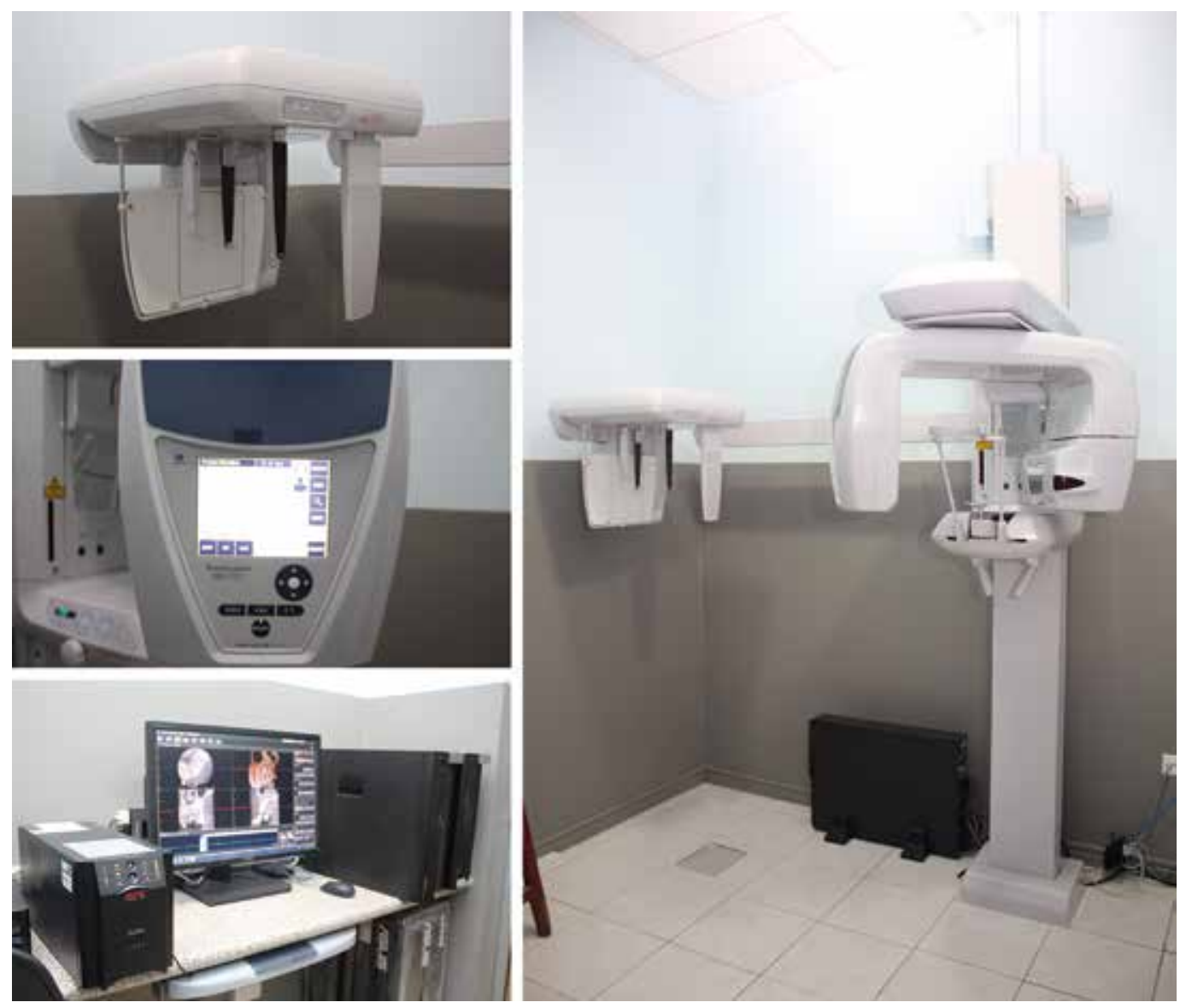

Figura 1.

Respecto a los procesos de digitalización, la Facultad contará con un sistema digital integrado de información que manejará los aspectos clínicos, docentes y administrativos, el cual ya lo aprobó el Comité Gerencial de Informática de la Universidad. La Facultad en años anteriores, ha gestionado acciones para obtener el expediente digital los cuales por una u otra razón no se había podido lograr. El decano de la Facultad, Dr. Carlos Filloy Esna, en el 2015, nombró a la Dirección de Servicios Odontológicos y Laboratorios para que coordinara la Comisión del Expediente Digital de la Facultad.

Esta comisión, representada por los directores de los departamentos académicos, la jefatura administrativa, la subdirección, un informático y la coordinación de mi persona, trabajó arduamente para lograr un proyecto de gran envergadura. Se le solicitó al rector la autorización para efectuar la búsqueda del software fuera de la Universidad, ya que el expediente que se estaba valorando desarrollar a través de una contratación de la Oficina de Bienestar y Salud no cubría ni siquiera un 30\% de lo requerido por nuestra academia. 
Una vez que se contó con el visto bueno de la Rectoría, dicha comisión se avocó a solicitar y convocar a varias empresas para licitar las ofertas de acuerdo a las necesidades de la Facultad, las cuales en diferentes reuniones presentaron su propuesta y alcances de cada una. Durante el proceso de selección, la comisión planteó la búsqueda de un sistema integrado y eficiente que automatice los procesos administrativos, clínicos, docentes e investigativos en beneficio de la operación y calidad de los servicios brindados en docencia, acción social e investigación, así como el apoyo para la toma de decisiones y rendición de cuentas de los diferentes niveles jerárquicos y gerenciales de la Facultad.

Finalizada esta etapa, se elevó la propuesta que se consideró más idónea a la Rectoría, que, a su vez, lo presentó al Comité Gerencial de Informática para una exhaustiva evaluación. Esto colateralmente nos ha llevado a un trabajo en conjunto con el Centro de Informática, que no ha permitido consolidar el proyecto, el cual fue gratamente aceptado por las autoridades universitarias y en estos momentos, incluso, se cuenta con una reserva presupuestaria en tanto se terminan de definir algunos detalles para su eventual implementación (12-13).

Así mismo, la educación debe ir de la mano con los avances tecnológicos y el estado del arte, para los cuales se necesita dar saltos cualitativos en la docencia en sus diferentes disciplinas, donde el recurso humano (docente) debe estar capacitado y homologado. Como política de la Facultad, se han venido efectuando congresos académicos semestrales para la actualización de su quehacer con base en la evidencia científica y criterio de expertos, para el apoyo del proceso enseñanza aprendizaje de los estudiantes, de los tratamientos y su evaluación, con la sistematización y revisión permanente de protocolos y rúbricas de evaluación (14).

Para concluir, es imprescindible resaltar la calidad del desarrollo en acción social a lo largo de los años, como una de las facultades con mayor proyección en esta área. La existencia de programas estructurados y sistemáticos del Curso de Externado Clínico, Campos de Trabajo Odontológicos, Ferias de Salud, Visitas Domiciliares, Programas de Atención a Personas con Necesidades Especiales, Trabajos de Campo en los distintos cursos de la carrera, Trabajo Comunal Universitario, a los que el estudiante está expuesto en su formación académica integral. En aras de mejorar el desarrollo de la formación en Odontología, la Facultad implementó el Curso de Asistentes Dentales desde el año 1967, hoy Técnicos Especializados en Asistencia Dental, programa pionero en su campo, con una gran evolución desde sus inicios, celebra sus 50 años de existencia en la facultad.

A grandes rasgos he querido plasmar en unas cuantas líneas los principales logros que ha tenido nuestra facultad en los últimos años, en donde todos, estudiantes, docentes y administrativos, hemos unido esfuerzos para

potenciar su excelencia. Esperamos con ansias seguir conquistando juntos nuevas metas, reinventándonos y buscando retos, orgullosos de pertenecer a esta casa de enseñanza, orgullosos de ser UCR.

\section{REFERENCIAS}

1. Facultad de Odontología. Acta de la Asamblea de Facultad No. 5-07. San José, Costa Rica. Universidad de Costa Rica; 2007.

2. Howard M., Jiménez M. M. La Reforma Curricular de la Licenciatura de Odontología en el Contexto del Proceso de Autoevaluación. Odovtos. 2009; 26-37. 
3. Universidad de Costa Rica. Estatuto Orgánico. Compendio de Normas Universitarias Usuales. San José, Costa Rica: Oficina Juríca; 2006.

4. Facultad de Odontología. Acta de la Asamblea de Facultad No. 2-03. San José, Costa Rica. Universidad de Costa Rica; 2003.

5. Howard M., Herrera J. J. El Proceso de Autoevaluación con fines de acreditación de la Carrera de Licenciatura en Odontología de la Universidad de Costa Rica. Revista Odovtos. 2009, 11: 5-9.

6. Comisión de Autoevaluación y Acreditación de la Facultad de Odontología. Compromiso de Mejoramiento de la Carrera de Licenciatura en Odontología ante SINAES. Periodo de Estudio 2004-2007. San José, Costa Rica: Universidad de Costa Rica; 21 de mayo 2009.

7. Filloy C., Howard M. El Compromiso de Mejoramiento de la Facultad de Odontología de la Universidad de Costa Rica con el Sistema Nacional de Acreditación de Educación Superior (SINAES). Revista Odovtos. 2009; 11: 64-72.

8. Facultad de Odontología. Comisión de Autoevaluación y Acreditación. Informe de Autoevaluación de la Facultad de Odontología de la Carrera de Licenciatura en Odontología para solicitar la acreditación ante el SINAES. Periodo de Estudio 2004-2007. San José, Costa Rica: Universidad de Costa Rica; 30 enero 2008.

9. Horner K., Hirschmann P. Dose reduction in dental radiography. J Dent, 1990; 18 (4): 171-184.

10. Shearer A. C., Horner K., Wilson N. H. Radio Visio Graphy for imaging root canals: an in vitro comparison with conventional radiography. Quintessence Int. 1990; 21 (10); 789-794.

11. Universidad de Costa Rica. Consejo Universitario. Políticas Universitarias 2016-2020. Excelencia e Innovación con Transparencia y Equidad. San José: Costa Rica; 2015.

12. Centro de Informática. Comité Gerencial. Oficio Respuesta a solicitud de autorización para expediente digital de la Facultad de Odontología. San José, Costa Rica: Universidad de Costa Rica, marzo, 2017.

13. Facultad de Odontología. Comisión Expediente Digital. Presentación "Necesidades de un Sistema Integral para el Manejo de la Información Digital de la Facultad de Odontología" a Comité Gerencial de Informática. San José, Costa Rica: Universidad de Costa Rica; agosto, 2016.

14. Facultad de Odontología. Congresos Académicos 2015-2017. San José, Costa Rica: Universidad de Costa Rica.

15. Facultad de Odontología. Guión para Video 75 Aniversario de la Fundación de la Universidad de Costa Rica. Ciudad Universitaria Rodrigo Facio. San José, Costa Rica. 2016.

\section{Dra. María Patricia Montero Chavarría. DDS, MSc ${ }^{1}$}

1. Máster en Salud Pública.

Directora, Dirección de Servicios Odontológicos y Laoratorios de la

Facultad de Odontología, Universidad de Costa Rica, Costa Rica.

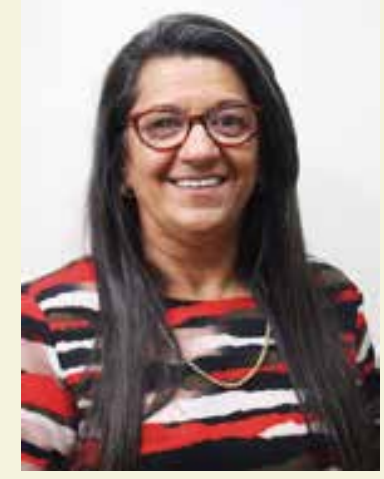

Attribution (BY-NC) - (BY) You must give appropriate credit, provide a link to the license, and indicate if changes were made. You may do so in any reasonable manner, but not in any way that suggest the licensor endorses you or your use. (NC) You may not use the material for commercial purposes. 